\title{
EFFECT OF EURASIAN SNOW COVER ON SUMMER CLIMATE OF THE NORTHERN HEMISPHERE: A GCM STUDY \\ (Abstract)
}

\author{
by \\ Tetsuzo Yasunari, \\ (Institute of Geoscience, University of Tsukuba, Ibaraki 305, Japan)
}

Akio Kitoh and Tatsushi Tokioka

(Meteorological Research Institute, Ibaraki 305, Japan)

\begin{abstract}
Observational studies have shown that Eurasian snow-cover anomalies during winter-through-spring seasons have a great effect on anomalies in atmospheric circulation and climate in the following summer season through snow albedo feedback (Hahn and Shukla, 1976; Dey and Bhanu Kumar, 1987). Morinaga and Yasunari (1987) have revealed that large-scale snow-cover extent over central Asia in late winter, which particularly has a great effect on the circulation over Eurasia in the following season, is closely related to the Eurasian pattern circulation (Wallace and Gutzler, 1981) in the beginning of winter.
\end{abstract}

Some atmospheric general circulation models (GCM) have suggested that not only the albedo effect of the snow cover but also the snow-hydrological process are important in producing the atmospheric anomalies in the following seasons (Yeh and others, 1984; Barnett and others, 1988).

However, more quantitative evaluations of these effects have not yet been examined. For example, it is not clear to what extent atmospheric anomalies are explained solely by snow-cover anomalies. Spatial and seasonal dependencies of these effects are supposed to be very large. Relative importance of snow cover over Tibetan Plateau should also be examined, particularly relevant to Asian summer monsoon anomalies. Moreover, these effects seem to be very sensitive to parameterizations of these physical processes (Yamazaki, 1988).

This study focuses on these problems by using some versions of GCMs of the Meteorological Research Institute. The results include the evaluation of total snow-cover feedbacks as part of internal dynamics of climatic change from 12-year GCM integration, and of the effect of anomalous snow cover over Eurasia in late winter on land surface conditions and atmospheric circulations in the succeeding seasons.

\section{REFERENCES}

Barnett, T., L. Dumenil, U. Schlese, E. Roeckner and M. Latif. 1989. The effect of Eurasian snow cover on regional and global climate variations. J. Atmos. Sci., 46, 661-685.

Dey, B. and O.S.R.U. Bhanu Kumar. 1983. Himalyan winter snow cover area and summer monsoon rainfall over India. J. Geophys. Res., 88, 5471-5474.

Hahn, D.J. and J. Shukla. 1976. An apparent relationship between Eurasian snow cover and Indian monsoon rainfall. J. Atmos. Sci., 33, 2461-2462.

Morinaga, Y. and T. Yasunari. 1987. Interactions between the snow cover and the atmospheric circulations in the northern hemisphere. IAHS Publication No. 166, 73-78.

Wallace, J.M. and D.S. Gutzler. 1981. Teleconnections in the geopotential height field during the northern hemisphere winter. Mon. Weather Rev., 109, 1542-1553.

Yamazaki, K. 1989. A study of the impact of soil moisture and surface albedo changes on global climate using the MRI . GCM-I. J. Meteor. Soc. Japan, 67, 123-146.

Yeh, T.C., R.T. Wetherald, and S. Manabe. 1983. A model study of the short-term climatic and hydrologic effects of sudden snow cover removal. Mon. Weather Rev., 111, 1013-1024. 